Pacific Journal of Mathematics

HERMITIAN LIFTINGS IN ORLICZ SEQUENCE SPACES

ONALD AlLen, David Alan Lego 


\title{
HERMITIAN LIFTINGS IN ORLICZ SEQUENCE SPACES
}

\author{
G. D. Allen, D. A. LegG and J. D. WARD
}

Let $M$ and $N$ be complimentary Orlicz functions satisfying the $A_{2}$-condition, and let $l_{M}$ and $l_{(M)}$ be the Orlicz sequence spaces associated with $M$ with the two usual norms. We show that if 2 is not in the associated interval for $M$, then every essentially Hermitian operator on $l_{M}$ or $l_{(M)}$ is a compact perturbation of a real diagonal operator.

1. Introduction. If $B$ is a unital Banach algebra, let $S=\left\{f \in B^{*}\right.$ : $f(e)=1=\|f\|\}$ be the state space and for each element $x \in B$, and set $W(x)=\{f(x): f \in S\}$. Let $X$ be a complex Banach space, $B(X)$ the space of bounded linear operators on $X$, and $C(X)$ the space of compact linear operators on $X$. The quotient algebra $A(X)=$ $B(X) / C(X)$ is called the Calkin algebra and both $B(X)$ and $A(X)$ lare unital Banach algebras. If $T \in B(X)$, the set $W(T)$ is called the numerical range of $T$, and the set $W_{e}(T)=\bigcap_{K \in C(X)} W(T+K)$ is called essential numerical range of $T$. An operator $T \in B(X)$ is called Hermitian if $W(T) \subseteq R$, the real line, and essentially Hermitian if $W_{e}(T) \cong R$.

Clearly any compact perturbation of a Hermitian operator $T \in$ $B(X)$ is essentially Hermitian, but the converse is by no means obvious. The converse is easy if $X$ is a Hilbert space, and has been shown to be true if $X=l_{p}, 1 \leqq p<\infty$, (cf. [1] and [4]). In this paper, we show the converse is true for those Orlicz sequence spaces $X$ for which 2 is not in the so called associated interval. This term is defined below.

2. Orlicz sequence spaces. We refer the reader to [3] and [6] for references on Orlicz spaces. In [3], Orlicz function spaces are considered, and many of the results translate directly into the sequence space setting.

In this paper, assume that $M$ is a continuous, strictly increasing, convex function defined on $[0, \infty)$, with $M(0)=0$, and $\lim _{t \rightarrow \infty} M(t)=\infty$. Any function $M$ satisfying these properties is called an Orlicz function. The complementary function will be denoted by $N$. We assume $M$ and $N$ both satisfy the $A_{2}$-condition; that is, there exists $K_{0}>0$ such that $M(2 t) \leqq K_{0} M(t)$ and $N(2 t) \leqq K_{0} N(t)$ for all $t$. By [5, Prop. 2.9 ], this means there exists $K_{1} \geqq 1$ such that

$$
1 \leqq \frac{t M^{\prime}(t)}{M(t)} \leqq K_{1} \quad \text { and } \quad 1 \leqq \frac{t N^{\prime}(t)}{N(t)} \leqq K_{1}
$$


for all $t$.

Since we are assuming the $\Delta_{2}$-condition, we may further assume that $p \equiv M^{\prime}$ and $q \equiv N^{\prime}$ are continuous and strictly increasing (cf. [5], Prop. 2.15). Recall also that $p$ and $q$ are inverse functions of each other.

The following are equivalent norms on the Orlicz sequence spaces:

$$
\begin{gathered}
\|\bar{a}\|_{M}=\left\|\left\{a_{n}\right\}\right\|_{M}=\inf \left\{k: \sum_{n=1}^{\infty} M\left(\frac{\left|a_{n}\right|}{k}\right) \leqq 1\right\} . \\
\|\bar{a}\|_{(M)}=\left\|\left\{a_{n}\right\}\right\|_{(M)}=\sup \left\{\left|\sum^{\infty} a_{n} b_{n}\right|: \sum_{n=1}^{\infty} N\left(\left|b_{n}\right|\right) \leqq 1\right\} .
\end{gathered}
$$

Note that $\|\bar{a}\|_{M}=1$ if and only if $\sum_{n=1}^{\infty} M\left(\left|a_{n}\right|\right)=1$. Denote by $l_{M}$ and $l_{(M)}$ the Orlicz sequence spaces endowed with the $\|\cdot\|_{M}$ and $\|\cdot\|_{(M)}$ norms, respectively. The dual space $l_{M}^{*}$ is isometrically isomorphic to $l_{(N)}$ (cf. [6], Prop. 4.b.1), and the dual space $l_{(M)}^{*}$ is isometrically isomorphic to $l_{N}$ (cf. [3], p. 135). Because both $M$ and $N$ are assumed to satisfy the $\Delta_{2}$-condition, $l_{M}$ (and $l_{N}$ ) are uniformly convex [7, Thm. 1] and thus reflexive (condition (iv) in Theorem 11 of [7] is extraneous in the case of sequence spaces as has been noted in [2, Theorem. 3]).

For each Orlicz function define the following two numbers:

$$
\begin{aligned}
& \alpha_{M}=\sup \left\{p: \sup _{0<\lambda, t \leqq 1} \frac{M(\lambda t)}{M(\lambda) t^{p}}<\infty\right\} \\
& \beta_{M}=\inf \left\{p: \inf _{0<\lambda, t \leqq 1} \frac{M(\lambda t)}{M(\lambda) t^{p}}>0\right\} .
\end{aligned}
$$

It is easy to see that $1 \leqq \alpha_{M} \leqq \beta_{M} \leqq \infty$, and that $\beta_{M}<\infty$ if and only if $M$ satisfies the $\Delta_{2}$-condition near 0 (cf. [6, Theorem 4.a.9]). Let $\alpha_{N}$ and $\beta_{N}$ be the values defined as above for the complementary function $N$. Then it is known that $\alpha_{M}^{-1}+\beta_{N}^{-1}=1$ and $\alpha_{N}^{-1}+\beta_{M}^{-1}=1$ (cf. [6, Theorem 4.b.3]). Hence if $M$ and $N$ satisfy the $\Delta_{2}$-condition, we have $1<\alpha_{M} \leqq \beta_{M}<\infty$ and $1<\alpha_{N} \leqq \beta_{N}<\infty$. The interval $\left[\alpha_{M}, \beta_{M}\right]$ is called the associated interval for $M$.

If $2<\alpha_{M} \leqq \beta_{M}<\infty, r$ and $s$ can be chosen so that $2<r<$ $\alpha_{M} \leqq \beta_{M}<s<\infty$. Then from (2) there is a constant $K_{4}<\infty$ such that

$$
\sup _{0<\lambda, t \leqq 1} \frac{M(\lambda t)}{M(\lambda) t^{r}}=K_{4}
$$

Using (1), (2) and the fact that $M(\lambda)=\int_{0}^{\lambda} p(t) d t \leqq \lambda p(\lambda)$ we have 


$$
\sup _{0<\lambda, t \leq 1} \frac{p(\lambda t)}{p(\lambda) t^{r-1}} \leqq \sup _{0<\lambda, t \leq 1} \frac{K_{1} M(\lambda t)}{\lambda t \lambda^{-1} M(\lambda) t^{r-1}}=K_{1} K_{4}=Q_{1}<\infty .
$$

Similarly, using (3) and (1), it follows that

$$
\inf _{0<\lambda, t \leqq 1} \frac{p(\lambda t)}{p(\lambda) t^{s-1}}=Q_{2}>0 .
$$

These inequalities will be used later.

\section{Vector states on $B\left(l_{M}\right)$ and $B\left(l_{(M)}\right)$.}

TheOREM 3.1. If $\bar{a}=\left\{a_{n}\right\}$ is a unit vector in $l_{M}$, let $\bar{a}^{\prime}=\left\{a_{n}^{\prime}\right\}$, where $a_{n}^{\prime}=k p\left(\left|a_{n}\right|\right) \operatorname{sgn} a_{n}$ and $k=\left\|\left\{p\left(\left|a_{n}\right|\right)\right\}\right\|_{(N)}^{-1}$. Then the mapping $A \rightarrow\left\langle A \bar{a}, \bar{a}^{\prime}\right\rangle$ defines a state on $B\left(l_{M}\right)$. Furthermore, there is a $K_{2}>0$ such that $K_{2} \leqq k \leqq 1$ for all unit vectors $\bar{a} \in l_{M}$.

Proof. $\quad \bar{a}^{\prime}$ is a unit vector in $l_{(N)}$ by the definition of $k$. Now $\|\bar{a}\|_{M}=1$ implies $\sum_{n=1}^{\infty} M\left(\left|a_{n}\right|\right)=1$, and this is the same as $\sum_{n=1}^{\infty} M\left(q\left(p\left(\left|a_{n}\right|\right)\right)\right)=1$. By [3, Theorem 10.4],

$$
\begin{aligned}
\left\langle\bar{a}, \bar{a}^{\prime}\right\rangle & =\sum_{n=1}^{\infty} a_{n} k p\left(\left|a_{n}\right|\right) \operatorname{sgn} \bar{a}_{n}=k \sum_{n=1}^{\infty}\left|a_{n}\right| p\left(\left|a_{n}\right|\right) \\
& =k \sum_{n=1}^{\infty}\left|p\left(\left|a_{n}\right|\right)\right| q\left(p\left(\left|a_{n}\right|\right)\right)=k\left\|\left\{p\left(\left|a_{n}\right|\right)\right\}\right\|_{(N)}=1 .
\end{aligned}
$$

Hence $A \rightarrow\left\langle A \bar{a}, \bar{a}^{\prime}\right\rangle$ defines a vector state on $B\left(l_{M}\right)$ for each unit vector $\bar{a} \in l_{M}$.

Since $\left\|\left\{p\left(\left|a_{n}\right|\right)\right\}\right\|_{(N)} \geqq 1$, it follows that $k \leqq 1$. Using (1) and the equality above, $\sum\left|a_{n}\right| p\left(\left|a_{n}\right|\right)=\left\|p\left(\left|a_{n}\right|\right)\right\|_{(N)}$, it follows that $\left\|\left\{p\left(\left|a_{n}\right|\right)\right\}\right\|_{(N)} \leqq$ $K_{1}$. Thus $K_{1}^{-1} \leqq k \leqq 1$. Take $K_{2}=K_{1}^{-1}$ and the proof is complete.

TheOREM 3.2. If $\bar{a}=\left\{a_{n}\right\}$ is a unit vector in $l_{(M)}$, let $\bar{a}^{\prime \prime}=\left\{a_{n}^{\prime \prime}\right\}$, where $a_{n}^{\prime \prime}=p\left(k\left|a_{n}\right|\right) \operatorname{sgn} a_{n}$ and $k>0$ is chosen so that $\sum N\left(p\left(k\left|a_{n}\right|\right)\right)=1$. Then the mapping $A \rightarrow\left\langle A \bar{a}, \bar{a}^{\prime \prime}\right\rangle$ defines a state on $B\left(l_{(M)}\right)$. Furthermore, there is a $K_{3} \geqq 1$ such that $1 \leqq k \leqq K_{3}$ for all unit vectors $\bar{a} \in l_{(M)}$.

Proof. The proof is similar to that of Theorem 3.1. In this case, note that

$$
\left\|\left\{a_{n}^{\prime \prime}\right\}\right\|_{N}=1=\left\|\left\{\frac{1}{k} q\left(\left|a_{n}^{\prime \prime}\right|\right)\right\}\right\|_{(M)}=\left\|\left\{\left|a_{n}\right|\right\}\right\|_{(M)} .
$$

It follows that $\left\langle\bar{a}, \bar{a}^{\prime \prime}\right\rangle=1 / k\left\|\left\{q\left(\left|a_{n}^{\prime \prime}\right|\right)\right\}\right\|_{(M)}=1$. So $A \rightarrow\left\langle A \bar{a}, \bar{a}^{\prime \prime}\right\rangle$ defines a vector state on $B\left(l_{(M)}\right)$ for each unit vector $\bar{a} \in l_{(M)}$. Also $K_{1}^{-1} \leqq k^{-1} \leqq 1$, so take $K_{3}=K_{1}$ and the proof is complete. 
4. Essentially Hermitian operators on $l_{M}$ or $l_{(M)}$. Let $A$ be an operator on $l_{M}$ or $l_{(M)}$ and define

$$
r_{i}(A)=\max \{|\operatorname{Im} z|: z \in W(A)\} .
$$

Let $\mathscr{P}$ be the set of projections onto the span of a subset of the canonical basis vectors for $l_{M}$ or $l_{(M)}$. If $P \in \mathscr{P}$, define $P^{\perp}=I-P$, where $I$ is the identity operator.

Our first result in this section is trivially true in the $l_{p}$ spaces $p \neq 2,1<p<\infty$, and is also true for the Orlicz spaces under consideration here. But due to the state structure in $l_{M}$ the result must be proved. Recall that throughout this paper $M$ and $N$ satisfy the $A_{2}$-condition and hence that $l_{M}$ is reflexive and uniformly convex.

Lemma 4.1. There is a constant $c>0$ so that $r_{i}(P A P)<\operatorname{cr}_{i}(A)$ for all $P \in \mathscr{P}$ and $A \in B\left(l_{M}\right)$.

Proof. Suppose for a given $A \in B\left(l_{M}\right)$ and $P \in \mathscr{P}$ with $P^{\perp}$ infinite dimensional that there exists a vector $\sigma=\left\{\sigma_{n}\right\}$ in $l_{M}$ for which $r_{i}(P A P) \equiv \delta=\operatorname{Im}\left\langle P A P \sigma, \sigma^{\prime}\right\rangle$. From Theorem 3.1, it follows that $\sigma^{\prime}=\left\{k p\left(\left|\sigma_{n}\right|\right) \operatorname{sgn} \sigma_{n}\right\}$ where $k=\left\|\left\{p\left(\left|\sigma_{n}\right|\right)\right\}\right\|_{(N)}^{-1}$ and that

$$
r_{i}(P A P)=k \operatorname{Im}\left\langle A \hat{\sigma},\left\{p\left(\left|\hat{\sigma}_{n}\right|\right) \operatorname{sgn} \hat{\sigma}_{n}\right\}\right\rangle
$$

where $\hat{\sigma}=\left\{\hat{\sigma}_{n}\right\}$ satisfies $P \hat{\sigma}=\sigma$ and $P^{\perp} \hat{\sigma}=0$. Clearly $\|\hat{\sigma}\| \leqq 1$. We wish to perturb $\hat{\sigma}$ into a unit vector $\gamma$ for which $\operatorname{Im}\left\langle A \gamma, \gamma^{\prime}\right\rangle \geqq c \delta$ for some $c>0, c$ independent of $\sigma, P$ and $A$. Since $l_{M}$ is reflexive the basis $\left\{e_{i}\right\}$ is shrinking [6]. Furthermore the sequences $\left\{e_{i}\right\}$ and $\left\{A e_{i}\right\}$ converge weakly to zero. From this it follows that for given $\varepsilon>0$, there exists an $N$ so that

$$
\left|\left\langle A\left(\hat{\sigma}+r e_{N}\right),\left(\hat{\sigma}+r e_{N}\right)^{\prime}\right\rangle-k^{\prime}\left\langle A \hat{\sigma},\left\{p\left(\left|\hat{\sigma}_{n}\right|\right) \operatorname{sgn} \hat{\sigma}_{n}\right\}\right\rangle-k^{\prime}\left\langle A r e_{N}, p(r) e_{N}^{\prime}\right\rangle\right|<\varepsilon
$$

where $0 \leqq r<1$ is chosen so that $\left\|\hat{\sigma}+r e_{N}\right\|=1$ and $k^{\prime}=$ $\left\|\left\{p\left(\hat{\sigma}_{n}\right), p(r)\right\}\right\|_{(N)}^{-1}$. From Theorem 3.1, $K_{2} \leqq k^{\prime} / k$. Hence it follows that

$$
\begin{aligned}
\operatorname{Im} & \left\langle A\left(\hat{\sigma}+r e_{N}\right),\left(\hat{\sigma}+r e_{N}\right)^{\prime}\right\rangle \\
& \geqq \operatorname{Im}\left[k^{\prime}\left\langle A \hat{\sigma},\left\{p\left(\left|\hat{\sigma}_{n}\right|\right) \operatorname{sgn} \hat{\sigma}_{n}\right\}\right\rangle+k^{\prime}\left\langle A r e_{N}, p(r) e_{N}^{\prime}\right\rangle\right]-\varepsilon .
\end{aligned}
$$

So

$$
r_{i}(A) \geqq \frac{k^{\prime}}{k}\left[k \operatorname{Im}\left\langle A \hat{\sigma},\left\{p\left(\left|\hat{\sigma}_{n}\right|\right) \operatorname{sgn} \hat{\sigma}_{n}\right\}\right\rangle+k \operatorname{Im}\left\langle A r e_{N}, p(r) e_{N}^{\prime}\right\rangle\right]-\varepsilon .
$$

Now if $\left|\operatorname{Im}\left\langle A e_{N}, e_{N}^{\prime}\right\rangle\right| \geqq K_{2} \delta / 2$, the lemma is proved with $c=K_{2} / 2$. So assume $\left|\operatorname{Im}\left\langle A e_{N}, e_{N}^{\prime}\right\rangle\right|\left\langle K_{2} \delta / 2\left(K_{2}\right.\right.$ as in Theorem 3.1). In this 
case, note that the quantities $r$ and $k p(r) K_{2}$ are less than or equal to 1 since $p(r) K_{2} k<p(r) k^{\prime}=p(r) /\|\{p(\hat{\sigma}), p(r)\}\|_{(N)}$ and it follows that

$$
\begin{aligned}
r_{i}(A) & \geqq \frac{k^{\prime}}{k}\left[\delta-k r p(r) K_{2} \delta / 2\right]-\varepsilon \\
& \geqq \frac{k^{\prime}}{k}[\delta / 2]-\varepsilon \geqq K_{2} \delta / 2-\varepsilon
\end{aligned}
$$

and the lemma still holds with $c=K_{2} / 2$.

Consider next the case $P \in \mathscr{P}$ with $P^{\perp}$ finite dimensional. Then $P$ eventually "looks like" the identity. Suppose for such $P, r_{i}(P A P)>$ $\operatorname{cr}_{i}(A)$ with $c$ as above. Then there exists a unit vector $\sigma$ such that

$$
\operatorname{Im}\left\langle P A P \sigma, \sigma^{\prime}\right\rangle>c r_{i}(A)
$$

and due to the continuity of the inner product assume $\sigma$ has finite support. The projection $P$ can now be altered to a projection $P^{\prime}$ for which $P^{\prime \perp}$ is infinite dimensional and $\operatorname{Im}\left\langle P^{\prime} A P^{\prime} \sigma, \sigma^{\prime}\right\rangle>c r_{i}(A)$. But this is impossible and so the lemma is valid for all projections.

LEMMA 4.2. If $2<\alpha_{M}$, then there is a constant $c_{M}$ such that $\sup _{P \in},\left\|P A P^{\perp}\right\| \leqq c_{M} r_{i}(A)$ for all $A \in B\left(l_{M}\right)$.

Proof. Let $A \in B\left(l_{M}\right)$ be fixed, and let $\sup _{P \in},\left\|P A P^{\perp}\right\|=\alpha$. Assume, without loss of generality, that the supremums of the above expression are attained; that is, there exists some $P \in \mathscr{P}$ and fixed unit vectors $\bar{a} \in l_{M}$ and $\bar{b}^{\prime} \in l_{(N)}$ satisfying $\alpha=\left\langle P A P^{\perp} \bar{a}, \bar{b}^{\prime}\right\rangle$. Letting $\bar{b}$ be associated with $\bar{b}^{\prime}$ as above (i.e., $\left\langle\bar{b}, \bar{b}^{\prime}\right\rangle=1,\|\bar{b}\|=1$ ) assume $P^{\perp} \bar{a}=\bar{a}, P \bar{b}=\bar{b}$. So $\bar{a}$ and $\bar{b}$ have disjoint supports. Let $\hat{\sigma}=c \bar{a}+$ $d \bar{b}$, where $c$ and $d$ are chosen so that $\|\hat{\sigma}\|_{M}=1$ and $c \operatorname{sgn} \bar{d}=i|c|$. Since $\sum_{n=1}^{\infty} M\left(|c|\left|a_{n}\right|+|d|\left|b_{n}\right|\right)=1$ and $M$ is convex, we must have $|d| \geqq 1-|c| \geqq 0$.

Now it follow that

$$
\begin{aligned}
r_{i}(A) \geqq & \left|\operatorname{Im}\left\langle A \bar{\sigma}, \bar{\sigma}^{\prime}\right\rangle\right| \\
= & \mid \operatorname{Im}\left\{\left\langle P A P^{\perp} \bar{\sigma}, \bar{\sigma}^{\prime}\right\rangle+\left\langle P^{\perp} A P^{\perp} \bar{\sigma}, \bar{\sigma}^{\prime}\right\rangle+\left\langle P^{\perp} A P \bar{\sigma}, \bar{\sigma}^{\prime}\right\rangle\right. \\
& \left.+\left\langle P A P \bar{\sigma}, \bar{\sigma}^{\prime}\right\rangle\right\} \mid \\
\geqq & \left|\operatorname{Im}\left\{\left\langle P A P^{\perp} \bar{\sigma}, \bar{\sigma}^{\prime}\right\rangle+\left\langle P^{\perp} A P \bar{\sigma}, \bar{\sigma}^{\prime}\right\rangle\right\}\right|-2 c r_{i}(A),
\end{aligned}
$$

where the last inequality follows from Lemma 4.1. Hence letting $c^{\prime}=2 c+1$ we have

$$
\begin{aligned}
c^{\prime} r_{i}(A) & \geqq\left|\operatorname{Im}\left\{\left\langle P A P^{\perp} \bar{\sigma}, \bar{\sigma}^{\prime}\right\rangle+\left\langle P^{\perp} A P \bar{\sigma}, \bar{\sigma}^{\prime}\right\rangle\right\}\right| \\
& =\mid \operatorname{Im}\left\{\sum_{n=1}^{\infty}\left(P A P^{\perp} \bar{a}\right)_{n} c k_{1} p\left(\left|d b_{n}\right|\right) \operatorname{sgn} \overline{d b_{n}}\right.
\end{aligned}
$$




$$
\begin{aligned}
& \left.+\sum_{n=1}^{\infty}\left(P^{\perp} A P \bar{b}\right)_{n} d k_{1} p\left(\left|c a_{n}\right|\right) \operatorname{sgn} \overline{c a_{n}}\right\} \mid \\
& =\mid \operatorname{Im}\left\{\sum_{n=1}^{\infty}\left(P A P^{\perp} \bar{a}\right)_{n} k_{2} p\left(\left|b_{n}\right|\right) \operatorname{sgn} \bar{b}_{n} \cdot c \operatorname{sgn} \bar{d} \frac{k_{1}}{k_{2}} \frac{p\left(\left|d b_{n}\right|\right)}{p\left(\left|b_{n}\right|\right)}\right. \\
& +\sum_{n=1}^{\infty}\left(P^{\perp} A P b\right)_{n} k_{3} p\left(\left|a_{n}\right|\right) \operatorname{sgn} \overline{\left(P^{\perp} A P b\right)_{n}} \\
& \left.\quad \times d \operatorname{sgn} \bar{c} \frac{k_{1}}{k_{3}} \frac{p\left(\left|c a_{n}\right|\right)}{p\left(\left|a_{n}\right|\right)} \frac{\operatorname{sgn} \bar{a}_{n}}{\operatorname{sgn} \overline{\left(P^{\perp} A \overline{P b}\right)_{n}}}\right\} \mid
\end{aligned}
$$

where $k_{1}, k_{2}$ and $k_{3}$ are the positive weights associated with $\bar{\sigma}^{\prime}, \bar{b}^{\prime}$, $\bar{a}^{\prime}$ as in Theorem 3.1 .

From (5) and (6), the inequality (7) continues as

$$
\begin{aligned}
c^{\prime} r_{i}(A) \geqq & \left|\operatorname{Im}\left\{\sum_{n=1}^{\infty}\left(P A P^{\perp} \bar{a}\right)_{n} k_{2} p\left(\left|b_{n}\right|\right) \operatorname{sgn} \bar{b}_{n} \cdot c \operatorname{sgn} \bar{d} \cdot \frac{k_{1}}{k_{2}} Q_{2}|d|^{s-1}\right\}\right| \\
& -\sum_{n=1}^{\infty}\left(P^{\perp} A P \bar{b}\right)_{n} k_{3} p\left(\left|a_{n}\right|\right) \operatorname{sgn}\left(\overline{P^{\perp} A P b}\right)_{n} \cdot|d| \cdot \frac{k_{1}}{k_{3}} Q_{1}|c|^{r-1}
\end{aligned}
$$

where each term in the second series is nonnegative. Since $c \operatorname{sgn} \bar{d}=$ $|c| i$ it follows from (5) that

$$
\begin{aligned}
c^{\prime} r_{i}(A) & \geqq\left\langle P A P^{\perp} \bar{a}, \bar{b}^{\prime}\right\rangle R_{2}^{\prime}|c||d|^{s-1}-\left\langle P^{\perp} A P \bar{b}, \bar{a}^{\prime \prime}\right\rangle R_{1}^{\prime}|d||c|^{r-1} \\
& \geqq\left\{R_{2}^{\prime}|c||d|^{s-1}-R_{1}^{\prime}|d \| c|^{r-1}\right\} \alpha \\
& \geqq\left\{R_{2}|c||d|^{s-1}-R_{1}|d||c|^{r-1}\right\} \alpha
\end{aligned}
$$

where

$$
R_{2}^{\prime}=\frac{k_{1}}{k_{2}} Q_{2}, \quad R_{1}^{\prime}=\frac{k_{1}}{k_{3}} Q_{1}, \quad R_{2}=K_{2} Q_{2}, \quad R_{1}=K_{2}^{-1} Q_{1}
$$

and $\bar{a}^{\prime \prime}=\left\{k_{3} p\left(\left|a_{n}\right|\right) \operatorname{sgn}\left({\overline{P^{\perp} A P b}}_{n}\right\}\right.$. Notice that the constants $R_{2}$ and $R_{1}$ are independent of the vectors $\bar{\sigma}, \bar{a}$ and $\bar{b}$. Now choose $|c|$ so small that

$$
\frac{\left(1-\left|c_{0}\right|\right)^{s-2}}{\left|c_{0}\right|^{r-2}}>2 \frac{R_{1}}{R_{2}}
$$

Then $R_{2}\left(1-\left|c_{0}\right|\right)^{s-2}>2 R_{1}\left|c_{0}\right|^{r-2}$, so $R_{2}\left(1-\left|c_{0}\right|\right)^{s-2}-R_{1}\left|c_{0}\right|^{r-2}>R_{1}\left|c_{0}\right|^{r-2}$. Finally, choose $c$ such that $|c|=\left|c_{0}\right|$. Recalling that $|d| \geqq 1-\left|c_{0}\right|$, it follows that

$$
\begin{aligned}
R_{2}|c||d|^{s-1}-R_{1}|d||c|^{r-1} & =\left|c_{0}\right||d|\left(R_{2}|d|^{s-2}-R_{1}\left|c_{0}\right|^{r-2}\right) \\
& \geqq\left|c_{0}\right||d|\left(R_{2}\left(1-\left|c_{0}\right|\right)^{s-2}-R_{1}\left|c_{0}\right|^{r-2}\right) \\
& \geqq\left.\left|c_{0}\right||d|\left|R_{1}\right| c_{0}\right|^{r-2} \\
& \geqq R_{1}\left|c_{0}\right|^{r-1}\left(1-\left|c_{0}\right|\right) .
\end{aligned}
$$

Hence by (9) and (10), we may take $c_{M}=c^{\prime}\left[R_{1}\left|c_{0}\right|^{r-1}\left(1-\left|c_{0}\right|\right)\right]^{-1}$ and the lemma is proved. 
LEMmA 4.3. If $2<\alpha_{M}$, then there exists a constant $c_{M}$ such that $\sup _{P \in \mathscr{G}}\left\|P A P^{\perp}\right\| \leqq c_{M} r_{i}(A)$ for all $A \in B\left(l_{(M)}\right)$.

Proof. The proof is almost identical with the proof of Lemma 4.2 , with $\bar{b}^{\prime}$ replaced with $b^{\prime \prime}$ (of Theorem 3.2).

THEOREM 4.4. If $2 \notin\left[\alpha_{M}, \beta_{M}\right]$, then there exists a constant $c_{M}$ such that $\sup _{P \in \mathcal{G}}\left\|P A P^{\perp}\right\| \leqq c_{M} r_{i}(A)$ for all $A \in B\left(l_{M}\right)$ or $B\left(l_{(M)}\right)$.

Proof. If $2<\alpha_{M}$, the conclusion follows from Lemmas 4.2 and 4.3. If $1<\alpha_{M} \leqq \beta_{M}<2$, then consider the transpose operator $A^{t} \in$ $B\left(l_{(N)}\right)$ or $B\left(l_{N}\right)$. From the above relations between $\alpha_{M}, \beta_{N}$ and $\beta_{M}$, $\alpha_{N}$, and since $2<\alpha_{N} \leqq \beta_{N}<\infty$, the conclusion follows from Lemmas 4.2 and 4.3 .

REMARK. Theorem 4.4 implies that Hermitian elements in $B\left(l_{M}\right)$ or $B\left(l_{(M)}\right), 2 \notin\left[\alpha_{M}, \beta_{M}\right]$, must be diagonal with respect to the canonical basis. Results of this type were first obtained by Tam (see [8]).

THEOREM 4.5. If $A \in B\left(l_{M}\right)$ or $B\left(l_{(M)}\right)$, then $\|A-\operatorname{diam} A\| \leqq$ $8 \sup _{P \in \mathscr{O}}\left\|P A P^{\perp}\right\|$.

The proof of this result requires nothing special about the function $M$. Indeed, below, we sketch the proof which in detail can be found in [1], Lemmas $3,4,5$ and 6 . Since $l_{M}$ is reflexive, the canonical basis $\left\{e_{i}\right\}$ is unconditionally monotone and shrinking. From those facts it can be verified that there are diagonal operators $u_{k} \in$ $B\left(l_{M}\right)$ for which $\bar{u}_{k} u_{k}=1$ and for which the

$$
\lim _{n \rightarrow \infty} \sum_{k=1}^{n} \frac{1}{n}\left(\bar{u}_{k} A u_{k}\right)=\operatorname{diag} A,
$$

with the limit being taken in the $w^{*}$ topology of $B\left(l_{M}\right)$. With this and the $w^{*}$-lower-semicontinuity of the norm it follows that

$$
\begin{aligned}
&\|\operatorname{diag} A-A\| \leqq \limsup _{n \rightarrow \infty}\left\|\sum_{k=1}^{n} \bar{u}_{k} A u_{k}-A\right\| \\
& \leqq \limsup _{n \rightarrow \infty} \max _{1 \leq k \leq n}\left\|A u_{k}-u_{k} A\right\| \\
& \leqq \sup \{\|S A-A S\|: S \text { is a diagonal operator in } \\
&\left.B\left(l_{M}\right),\|S\|=1\right\} .
\end{aligned}
$$

Finally, by a result of Arveson [1, Lemma 6], this quantity is shown to be $\leqq 8 \sup _{P \in \mathscr{G}}\left\|P A P^{\perp}\right\|$. This completes a sketch of the proof of the theorem. 
THEOREM 4.6. Let $2 \notin\left[\alpha_{M}, \beta_{M}\right]$. If $A$ is an essentially Hermitian operator in $B\left(l_{M}\right)$ or $B\left(l_{(M)}\right)$, then there is a real diagonal operator $D$ and a compact operator $K$ such that $A=D+K$.

Proof. We show that $A-\operatorname{Re} \operatorname{diag} A$ is compact. Suppose that $\operatorname{diag} A=\operatorname{Re} \operatorname{diag} A$, since $\operatorname{Im} \operatorname{diag} A$ must be compact for essentially Hermitian operators. Recall that $P_{n}^{\perp}$ is the projection onto span $\left\{e_{n+1}, e_{n+2}, \cdots\right\}$. If $r_{i}\left((A-\right.$ re $\left.\operatorname{diag} A) P_{n}^{\perp}\right)$ is not convergent to zero as $n \rightarrow \infty$, it is simple to construct a sequence of mutually disjoint norm one vectors $v_{n}$ for which $\inf _{n}\left|\operatorname{Im}\left\langle(A-\operatorname{Re} \operatorname{diag} A) v_{n}, v_{n}^{\prime}\right\rangle\right|=$ $k>0$. If glim denotes Banach limit, then $\phi(\cdot) \equiv \operatorname{glim}\left\langle\cdot v_{n}, v_{n}^{\prime}\right\rangle$ is a state on the Calkin algebra for which $\operatorname{Im} \phi(A)=k>0$. This contradicts the hypothesis that $A$ is essentially Hermitian. Hence by Theorems 4.4 and 4.5 it follows that $\left\|(A-\operatorname{Re} \operatorname{diag} A) P_{n}^{\perp}\right\| \rightarrow 0$ as $n \rightarrow \infty$. This means that, in the uniform norm,

$$
\lim _{n \rightarrow \infty}(A-\operatorname{Re} \operatorname{diag} A) P_{n}=A-\operatorname{Re} \operatorname{diag} A .
$$

Since each $P_{n}$ is compact, the theorem is proved.

5. Concluding remarks. It is conjectured that if $2 \in\left[\alpha_{M}, \beta_{M}\right]$ the main result does not hold in general. The reason is this: if $2 \epsilon$ $\left[\alpha_{M}, \beta_{M}\right]$ then $l_{M}$ contains a subspace isomorphic to $l_{2}$, and indeed the subspace can even be complemented. However even with the assumption that $l_{M}$ contains a complemented subspace isomorphic to $l_{2}$ we have been unable to establish the conjecture. The existence of the isomorphism is simply not enough; in fact there is a modular Orlicz sequence space, isomorphic to $l_{2}$, which contains only diagonal Hermitian operators.

The analogous result to Theorem 4.5 in Orlicz function spaces, even in $L_{p} 1 \leqq p<\infty$, is another matter altogether and it is posed as an open problem.

\section{REFERENCES}

1. G. D. Allen and J. D. Ward, Hermitian liftings in $B\left(l_{p}\right)$, J. Operator Theory, to appear.

2. Z. Altshuler, The modulus of convexity of Lorentz sequence and Orlicz spaces, preprint.

3. M. A. Krasnosel'skii and Y. R. Rutickii, Convex Functions and Orlicz spaces, Groningen, 1961.

4. D. A. Legg and J. D. Ward, Essentially Hermitian operators on $l_{1}$ are compact perturbations of Hermitians, Proc. Amer. Math. Soc., 67 No. 2 (1977), 224-226.

5. K. Lindberg, On subspaces of Orlicz sequence spaces, Studia Math., XLV (1973), 119-146.

6. J. Lindenstrauss and L. Tzafriri, Classical Banach Spaces I, Sequence Spaces, Springer-Verlag, Berlin, 1977. 
7. H. W. Milnes, Convexity of Orlicz speces, Pacific J. Math., 7 (1957), 1451-1483.

8. K. W. Tam, Isometries of certain function spaces, Pacific J. Math., 31 No. 1 (1969), 233-246.

Received August 2, 1978 and in revised form June 8, 1979.

TeXas A \& M University

College Station, TX 77843 



\title{
PACIFIC JOURNAL OF MATHEMATICS
}

\section{EDITORS}

\author{
DoNALD BABBITT (Managing Editor) \\ University of California \\ Los Angeles, CA 90024 \\ HUGo RossI \\ University of Utah \\ Salt Lake City, UT 84112 \\ C. C. MOORE and ANDREW OGG \\ University of California \\ Berkeley, CA 94720
}

J. DugundJI

Department of Mathematics

University of Southern California

Los Angeles, CA 90007

R. FINN and J. Milgram

Stanford University

Stanford, CA 94305

\section{ASSOCIATE EDITORS}
E. F. BeCKenbach
B. H. NeumanN
F. WOLF
K. YoshidA

\section{SUPPORTING INSTITUTIONS}

\author{
UNIVERSITY OF BRITISH COLUMBIA \\ CALIFORNIA INSTITUTE OF TECHNOLOGY \\ UNIVERSITY OF CALIFORNIA \\ MONTANA STATE UNIVERSITY \\ UNIVERSITY OF NEVADA, RENO \\ NEW MEXICO STATE UNIVERSITY \\ OREGON STATE UNIVERSITY \\ UNIVERSITY OF OREGON
}

\author{
UNIVERSITY OF SOUTHERN CALIFORNIA \\ STANFORD UNIVERSITY \\ UNIVERSITY OF HAWAII \\ UNIVERSITY OF TOKYO \\ UNIVERSITY OF UTAH \\ WASHINGTON STATE UNIVERSITY \\ UNIVERSITY OF WASHINGTON
}

The Supporting Institutions listed above contribute to the cost of publication of this Journal, but they are not owners or publishers and have no responsibility for its content or policies.

Mathematical papers intended for publication in the Pacific Journal of Mathematics should be in typed form or offset-reproduced, (not dittoed), double spaced with large margins. Please do not use built up fractions in the text of the manuscript. However, you may use them in the displayed equations. Underline Greek letters in red, German in green, and script in blue. The first paragraph or two must be capable of being used separately as a synopsis of the entire paper. Please propose a heading for the odd numbered pages of less than 35 characters. Manuscripts, in triplicate, may be sent to any one of the editors. Please classify according to the scheme of Math. Reviews, Index to Vol. 39. Supply name and address of author to whom proofs should be sent. All other communications should be addressed to the managing editor, or Elaine Barth, University of California, Los Angeles, California, 90024.

50 reprints to each author are provided free for each article, only if page charges have been substantially paid. Additional copies may be obtained at cost in multiples of 50 .

The Pacific Journal of Mathematics is issued monthly as of January 1966. Regular subscription rate: $\$ 84.00$ a year $(6$ Vols., 12 issues). Special rato: $\$ 42.00$ a year to individual members of supporting institutions.

Subscriptions, orders for numbers issued in the last three calendar years, and changes of address shoud be sent to Pacific Journal of Mathematics, P.O. Box 969, Carmel Valley, CA 93924, U.S.A Old back numbers obtainable from Kraus Periodicals Co., Route 100, Millwood, NY 10546.

\section{PUBLISHED BY PACIFIC JOURNAL OF MATHEMATICS, A NON-PROFIT CORPORATION}

Printed at Kokusai Bunken Insatsusha (International Academic Printing Co., Ltd.). 8-8, 3-chome, Takadanobaba, Shinjuku-ku, Tokyo 160, Japan. 


\section{Pacific Journal of Mathematics}

\section{Vol. 86, No. 2 December, 1980}

Graham Donald Allen, David Alan Legg and Joseph Dinneen Ward, Hermitian

liftings in Orlicz sequence spaces ............................... 379

George Bachman and Alan Sultan, On regular extensions of measures ........ 389

Bruce Alan Barnes, Representations Naimark-related to $*$-representations; a

correction: "When is a representation of a Banach $*$-algebra

Naimark-related to a $*$-representation?" ........................ 397

Earl Robert Berkson, One-parameter semigroups of isometries into $H^{p} \ldots \ldots .403$

M. Brodmann, Piecewise catenarian and going between rings ............ 415

Joe Peter Buhler, A note on tamely ramified polynomials ............... 421

William Lee Bynum, Normal structure coefficients for Banach spaces ........ 427

Lung O. Chung, Biharmonic and polyharmonic principal functions ......... 437

Vladimir Drobot and S. McDonald, Approximation properties of polynomials

with bounded integer coefficients .............................

Giora Dula and Elyahu Katz, Recursion formulas for the homology of

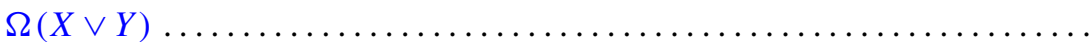

John A. Ernest, The computation of the generalized spectrum of certain Toeplitz operators ...................................... 463

Kenneth R. Goodearl and Thomas Benny Rushing, Direct limit groups and the

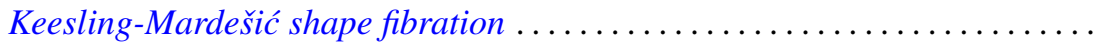

Raymond Heitmann and Stephen Joseph McAdam, Good chains with bad contractions

Patricia Jones and Steve Chong Hong Ligh, Finite hereditary near-ring-semigroups .

Yoshikazu Katayama, Isomorphisms of the Fourier algebras in crossed

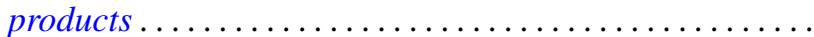

Meir Katchalski and Andrew Chiang-Fung Liu, Symmetric twins and common transversals. .

Mohammad Ahmad Khan, Chain conditions on subgroups of LCA groups ....

Helmut Kröger, Padé approximants on Banach space operator equations ...

Gabriel Michael Miller Obi, An algebraic extension of the Lax-Milgram theorem . .

S. G. Pandit, Differential systems with impulsive perturbation .

Richard Pell, Support point functions and the Loewner variation ...

J. Hyam Rubinstein, Dehn's lemma and handle decompositions of some

4-manifolds

James Eugene Shirey, On the theorem of Helley concerning finite-dimensional subspaces of a dual space.

Oved Shisha, Tchebycheff systems and best partial bases.... 